\title{
Simulation and Comparison of 2-L \& 3-L Inverter Fed Induction Motor DTC Drives
}

\author{
O.Chandra Sekhar and K.Chandra Sekhar
}

\begin{abstract}
Direct Torque Control is a control technique in AC drive systems to obtain high performance torque control. The conventional DTC drive contains a pair of hysteresis comparators. DTC drives utilizing hysteresis comparators suffer from high torque ripple and variable switching frequency. The most common solution to those problems is to use the space vector depends on the reference torque and flux. In this Paper The space vector modulation technique (SVPWM) is applied to Two level(2-L) inverter control in the proposed DTC-based induction motor drive system, there by dramatically reducing the torque ripple Then the controller based on space vector modulation is designed to be applied in the control of Induction Motor(IM)with a Three-level Inverter(3-L).This type o Inverter has several advantages over the standard two-level VSI, such as a greater number of levels in the output voltage waveforms, Lower $\mathrm{dV} / \mathrm{dt}$, less harmonic distortion in voltage and current waveforms and lower switching frequencies. This p a p e r proposes a g e n e a I SVPWM algorithm for threelevel inverter based on standard two-level inverter. The proposed scheme is described clearly and simulation results are reported to demonstrate its effectiveness. The entire control scheme is implemented with Matlab/Simulink.
\end{abstract}

Index Terms-DTC, Three-level Inverter, Two-level Inverter, Induction machine.

\section{INTRODUCTION}

Induction motors are the most widely used alternative in adjustable speed drives. Field Oriented Control (FOC) [1], and Direct Torque Control (DTC) [2,3] have emerged as the standard industrial solutions for high dynamic performance operation of these machines.

In particular DTC offers attractive performance in terms of fast torque response, simple and less computational cumbersome control schemes, robustness against parameter variation, no need of PWM modulator and current regulators. However it has some draw backs like torque ripple, variable switching frequency, electromagnetic compatibility due to high frequency harmonic current and voltage. In recent years, research is going on DTC for multi level converters $[5,6,9]$ but most of the control techniques require predictive algorithms. These techniques use complex control schemes which are difficult to implement. On the other hand, Multilevel Inverters have become a very

Manuscript received April 29, 2011; revised July 12, 2011.

O.Chandrasekhar, is with the Department of Electrical and Electronics Engineering, Vignan's Lara Institute of Technology \& Science, Vadlamudi, Guntur, Andhra Pradesh ,522213, India (phone: +91 9440343273); Fax: +91 8632118456; e-mail: Sekhar.obbu@gmail.com.

Dr.K.Chandrasekhar,is with the Department of Electrical and Electronics Engineering,R.V.R\&J.CCollege of Engineering, Chowdavaram, Guntur, Andhra Pradesh ,522019 India (phone: +91 9393194449);e-mail: cskoritala@gmail.com. attractive solution for high power applications, due to higher voltage operation capability, reduced common mode voltages, near sinusoidal outputs, low $d v / d t$ 's and smaller or even no output filter [4]. The most attractive features of this technology are in the medium to high-voltage application range $(2-13 \mathrm{kV})$, which include motor drives, power distribution, power quality and power conditioning applications [13]. One of the advantages of multilevel inverters is that the voltage stress on each switching device is reduced. In addition, multilevel waveforms feature have less harmonic content compared to two level waveforms operating at the same switching frequency .In multi level inverters, it is easy to reach high voltage levels in high power applications with lower harmonic distortion and switching frequency, which is very difficult to get this performance with conventional two level inverters. The high-voltage switches are rather expensive, the employment of the double number of the cheaper switches are often economical favorable. Simultaneously the less IM current and torque distortions can be achieved by using of the more number of the feasible inverter states [9].

In this paper two different DTC schemes will be compared with each other. These two schemes are DTCSVM with two-level inverter and DTC-SVM with threelevel inverter. The Proposed scheme is described clearly and simulation results are reported to demonstrate its effectiveness. The entire control scheme is implemented with Matlab/Simulink.

\section{DTC-SVM WITH TWO-LEVEL INVERTER}

Fig. 1 shows the schematic of The basic functional blocks used to implement the DTC of induction motor drive. A voltage source inverter (VSI) supplies the motor and it is possible to control directly the stator flux and the electromagnetic torque by the selection of optimum inverter switching modes [1]-[4]

\section{A. Vector Model of Inverter Output Voltage}

In the PWM voltage source inverters, considering the combinations of the states of switching functions inverter switching state functions $(\mathrm{C} 1, \mathrm{C} 2$, and $\mathrm{C} 3$ ) which can take either 1 or 0 , the voltage vector becomes.

Eight switching combinations can be taken according to the above relationship: two zero voltage vectors and six non-zero voltage vectors show by Fig.2 [1][2].

\section{B. Stator Flux and Torque Estimation}

The components of the current (Is $\alpha$, Is $\beta$ ), and stator voltage $(\mathrm{Vs} \alpha, \mathrm{Vs} \beta)$ are obtained by the application of the transformation given by (5) and (6), [1]

$$
V_{S}=\sqrt{\frac{2}{3} U_{O}\left[C_{1}+C_{2} e^{J \frac{2 \pi}{3}}+C_{3} e^{J \frac{4 \pi}{3}}\right]}
$$




$$
\begin{gathered}
I_{S \alpha}=\sqrt{\frac{2}{3} I_{S A}} \\
I_{S \beta}=\frac{1}{\sqrt{2}}\left(I_{S B}-I_{S C}\right) \\
V_{S \alpha}=\sqrt{\frac{2}{3}} \mathrm{U}_{0}\left(C_{1}-\frac{1}{2}\left(C_{2}+C_{3}\right)\right) \\
V_{S \beta}=\frac{1}{\sqrt{2}} U_{0}\left(C_{2}-C_{3}\right)
\end{gathered}
$$

The components of the stator flux $(\varphi s \alpha, \varphi s \beta)$ given by (5).

$$
\begin{aligned}
& \bar{\varphi}_{S \alpha}=\int_{0}^{t}\left(\bar{V}_{S \alpha}-R_{S} \bar{I}_{S \alpha}\right) d t \\
& \varphi_{S \beta}=\int_{0}^{t}\left(\bar{V}_{S \alpha}-R_{S} \bar{I}_{S \beta}\right) d t
\end{aligned}
$$

The stator flux linkage phase is given by (6).

$$
\varphi_{S}=\sqrt{\varphi_{S \alpha}^{2}+\varphi_{S \beta}^{2}}
$$

The electromagnetic couple be obtained starting from the estimated sizes of flux ( $\varphi$ s $\alpha, \varphi s \beta$ and calculated sizes of the current, Is $\alpha$ Is $\beta$ )

$$
\Gamma_{e m}=\mathrm{P}\left(\varphi_{S \alpha} I_{S \beta}-\varphi_{S \beta} I_{S \alpha}\right)
$$

The stator resistance Rs can be assumed constant during a large number of converter switching periods Te. The voltage vector applied to the induction motor remains also constant one period Te. Therefore, resolving first equation of system leads to:

$$
\begin{aligned}
& \bar{\varphi}_{S}=\int_{0}^{t}\left(\bar{V}_{S}-R_{S} \bar{I}_{S}\right) d t \\
& \bar{\varphi}_{S}(t) \approx \bar{\varphi}_{S 0}+\bar{V}_{S} T_{e}
\end{aligned}
$$

In equation (11); $\varphi s 0$ stands for the initial stator flux condition. This equation shows that when the term RsIs can be neglected, (in high speed operating condition for example), the extremity of stator flux vector Vs. Furthermore, the instantaneous flux speed is only governed by voltage vector amplitude [1][4].

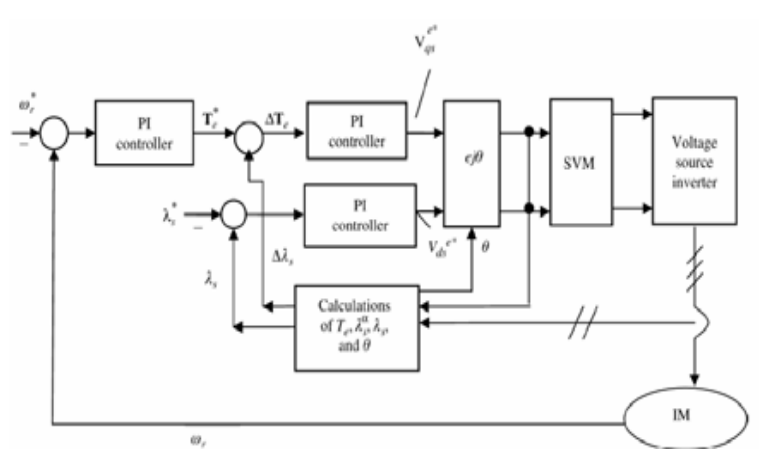

Fig. 1. Basic direct torque control scheme for ac motor drives.

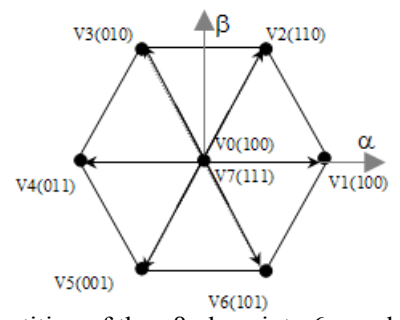

Fig. 2. Partition of the $\alpha \beta$ plane into 6 angular sectors
In fact, we have $\frac{d \bar{\varphi}_{S}}{d t} \approx \bar{V}_{S}$ the following Fig.3 Established for the case $\mathrm{Vs}_{\mathrm{S}}=\mathrm{V} 3$. Therefore, by adequate voltage vector selection we can increase or decrease the stator flux amplitude and phase to obtain the required performances. The deviation obtained at the end of the switching period Te can be approached by the first order Taylor Seri as below.

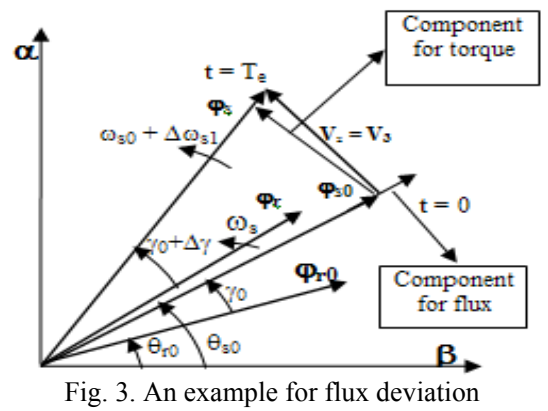

The radial component (component of flux) of the vector of tension acts on the amplitude of the vector flux and its tangential component (component of the torque) on the position of the vector flux. By choosing a suitable sequence of the vectors of tension, one can force the end of the vector flux to follow a desired trajectory. To function with a module of practically constant flux $\varphi s$, it is enough to choose an almost circular trajectory for the end of the vector flux. That is not possible that if the period of control is very weak for you in front of the period of rotation of flux [1], [3] [10].

\section{Switching Table}

On the basis of the torque and flux hysteresis status and of the stator flux switching sector, which is denoted by $\alpha$, DTC algorithm selects the inverter voltage vector to apply to the induction machine from the Table 1 . The outputs of the switching table are the settings for the switching devices of the inverter. Figure 4 shows the relation of inverter voltage vector and the stator flux switching sectors.

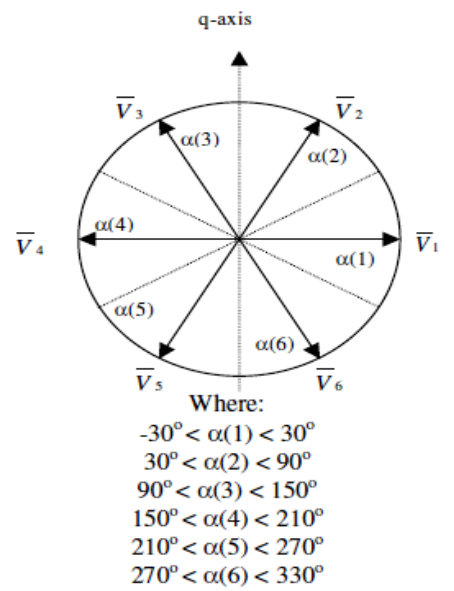

Fig. 4. Inverter voltage vectors and stator flux switching sector

$$
\alpha=\angle \bar{\psi}_{s}^{s}=\tan ^{-1}\left(\frac{\Psi_{q s}^{s}}{\Psi_{d s}^{s}}\right)
$$

Active switching vectors:

$$
\begin{aligned}
& \bar{V}_{1}(100) ; \bar{V}_{2}(110) ; \\
& \overline{\mathrm{V}}_{3}(010) ; \bar{V}_{4}(011) ; \\
& \bar{V}_{5}(001) ; \bar{V}_{6}(101)
\end{aligned}
$$


Zero switching vectors:

$$
\bar{V}_{0}(000) ; \bar{V}_{7}(111)
$$

TABLE1: SWITCHING TABLE OF INVERTER VOLTAGE VECTORS

\begin{tabular}{|c|c|c|c|c|c|c|c|}
\hline $\mathrm{d} \psi$ & $\mathrm{d} T_{\mathrm{e}}$ & $\begin{array}{l}\alpha(1) \\
\text { sector1 }\end{array}$ & $\begin{array}{l}\alpha(2) \\
\text { sector2 }\end{array}$ & $\begin{array}{l}\alpha(3) \\
\text { sector3 }\end{array}$ & $\begin{array}{l}\alpha(4) \\
\text { sector4 }\end{array}$ & $\begin{array}{l}\alpha(5) \\
\text { sector5 }\end{array}$ & $\begin{array}{l}\alpha(6) \\
\text { sector6 }\end{array}$ \\
\hline \multirow[t]{3}{*}{1} & 1 & $\bar{V} 2$ & $\bar{V}_{3}$ & $\bar{V}_{4}$ & $\bar{V} 5$ & $\bar{V}_{6}$ & $\bar{V}_{1}$ \\
\hline & 0 & $\overline{V_{7}}$ & $\bar{V} 0$ & $\bar{V} 7$ & $\bar{V} 0$ & $\bar{V} 7$ & $\bar{V}_{0}$ \\
\hline & $\overline{1}$ & $\bar{V}_{6}$ & $\bar{V}_{1}$ & $\bar{V} 2$ & $\bar{V}_{3}$ & $\bar{V}_{4}$ & $\bar{V}_{5}$ \\
\hline \multirow[t]{3}{*}{0} & 1 & $\bar{V}_{3}$ & $\bar{V}_{4}$ & $\bar{V} 5$ & $\bar{V}_{6}$ & $\bar{V}_{1}$ & $\bar{V} 2$ \\
\hline & 0 & $\bar{V}_{0}$ & $\bar{V}_{7}$ & $\bar{V} 0$ & $\overline{V_{7}}$ & $\bar{V} 0$ & $\overline{V_{7}}$ \\
\hline & $\overline{1}$ & $\bar{V} 5$ & $\bar{V} 6$ & $\bar{V}_{1}$ & $\bar{V}_{2}$ & $\bar{V}_{3}$ & $\bar{V}_{4}$ \\
\hline
\end{tabular}

\section{DTC-SVM WITH THREE-LEVEL INVERTER}

In this scheme the block diagram is exactly like Fig. 1 but the only difference between two schemes is that three-level inverter will be replaced instead of two-level inverter. Multilevel inverters are increasingly being used in highpower medium voltage applications due to their superior performance compared to two-level inverters, such as lower common-mode voltage, lower $\mathrm{dv} / \mathrm{dt}$, lower harmonics in output voltage and current and reduced voltage on the power switches. Among various modulation technique for a multilevel inverter, space vector pulse width modulation (SVPWM) is an attractive candidate due to the following merits. It directly uses the control variable given by the control system and identifies each switching vector as a point in complex $(\alpha, \beta)$ space. It is suitable for digital signal processor (DSP) implementation. It can optimize switching sequences.

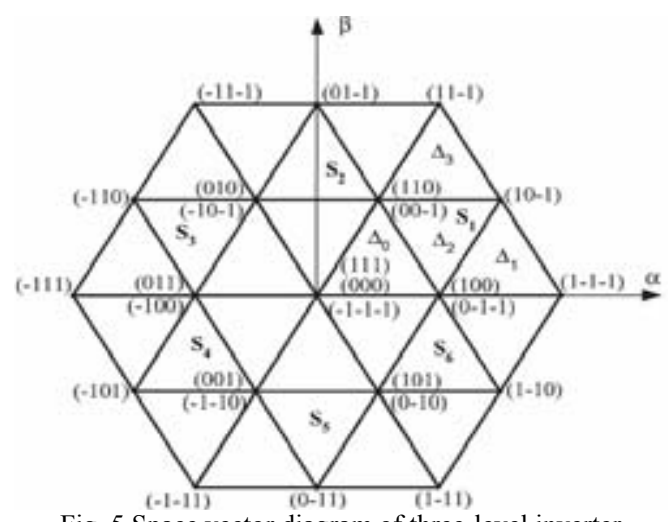

Fig. 5.Space vector diagram of three-level inverter

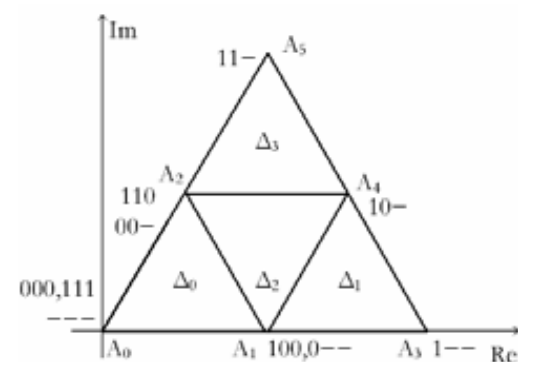

Fig. 6. Division of each sector to four triangles

Fig.5 shows the space vector diagram of a three-level inverter. There are six sectors (S1-S6), four triangles $(\Delta 0$ $\Delta 3)$ in a sector, and a total of 27 switching states in this space vector diagram. As a method outlined in [7] suggests, each sector of the outer hexagon of three-level SVM can be divided into four smaller triangles, indexed as shown in Fig. 5. Each of these smaller triangles are then considered as one sector of a two level hexagon, with the same redundancy at the origin.

In this method, the triangle that bounds the reference vector is found based on coordinates of the tip of the reference vector. The origin $(0,0)$ is then moved to the origin-vertex of the corresponding triangle. The triangles are determined by firs calculating auxiliary parameters $\mathrm{k} 1$ and $\mathrm{k} 2$ which are defined as:

$$
\begin{aligned}
& k_{1}=\left[V_{\alpha}+\frac{V_{\beta}}{\sqrt{3}}\right] \\
& K_{2}=\left[\frac{V_{\beta}}{\frac{\sqrt{3}}{2}}\right]
\end{aligned}
$$

$\mathrm{V} \alpha$ and $\mathrm{V} \beta$ are coordinates of the tip of the space vector, $\mathrm{k} 1$ determines whether the small triangle is in the right-hand side of the sector $(\mathrm{k} 1=1)$ or in the left-hand side $(\mathrm{k} 1=0) . \mathrm{k} 2$ determines if it is in the upper half $(\mathrm{k} 2=1)$ or in the lower half $(\mathrm{k} 2=0)$. The reference vector is shifted to the new set of axes that intersect at the main vertex (or origin) of the triangle. Assuming a type one triangle, the coordinates of the tip of the shifted reference vector $\overline{A_{i}} \bar{P}$, where $\mathrm{P}=(\mathrm{V} \alpha$, $\mathrm{V} \beta)$ is the tipoff the original space vector and $i A$ is the origin of the triangle, are found as follows.

$$
\begin{aligned}
& V_{\alpha i}=V_{\alpha}-k_{1}+\frac{1}{2} k_{2} \\
& V_{\beta I}=V_{\beta}-\frac{\sqrt{3}}{2} k_{2}
\end{aligned}
$$

The triangle index is found from:

$$
\Delta=k_{1}^{2}+2 k_{2}
$$

Once the shifted reference is found, time shares are calculated similar to the two-level case. Using shifted Coordinates, Ta(duration of the space-vector aligned with the $\alpha$-axis), $\mathrm{Tb}$ (duration of the space-vector at $60^{\circ}$ from the $\alpha$ - axis) and $\mathrm{Tz}$ (duration of zero space-vectors) can be found from the following.

$$
\begin{aligned}
& T_{a}=T_{s}\left(V_{\alpha i}-\frac{V_{\beta i}}{\sqrt{3}}\right) \\
& T_{b}=T_{s}\left(\frac{V_{\beta i}}{\sqrt{3}}\right) \\
& T_{Z}=T_{s}-T_{a}-T_{b}
\end{aligned}
$$

The three nearest space vectors are used to synthesize the reference vector. These vectors correspond to the vertices of the bounding triangle. The sequence of vectors in the first sector is determined by inspection. For other sectors, the states are found from the mapping of switching states between the first sector and other sectors. The switch states are left unchanged for the first sector, but for other sectors they are changed accordingly so that they use the available space-vector in other sectors. For maintaining the balance of capacitor voltages, the spacevector sequences can be chosen in a way that the available redundancies lead to sharing of 
current of each leg equally between the respective capacitors.

\section{SiMULATION AND RESULTS}

To show the effectiveness of the DTC-SVM with three level inverter and SVPWM switching technique a simulation work has been carried out on induction motor with the specifications given in Appendix. The proposed scheme is simulated with Matlab/Simulink. Fig. 7 shows the simulation results. Fig. 7(a) shows the torque response with the DTC-SVM with two-level inverter scheme with the same load torque, from this response it is observed that the ripple in the torque response is around 7.5 Nm. Fig. 7(b) shows the torque response with the DTC-SVM with threelevel inverter scheme with the same load torque, here the torque ripple is around $3.3 \mathrm{Nm}$. This results show that the torque ripples in the three-level scheme has been reduced significantly.

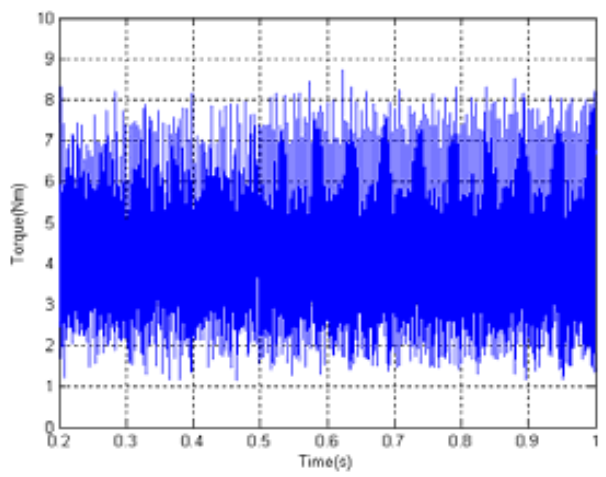

(a) DTC-SVM (Two-level Inverter)

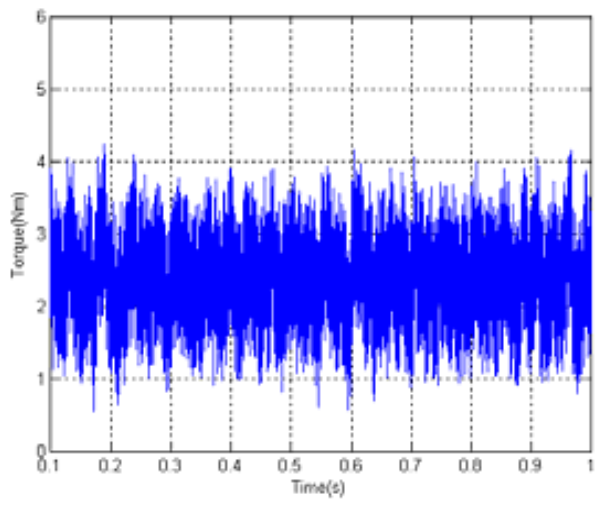

(b) DTC-SVM (Three-level Inverter)

Fig. 7. Torque Response

From the simulation results presented in Fig.8 Flux response for 3-level, 2-level inverter fed induction motor are shown. The comparison is carried for a given machine at similar conditions. From fig 8 flux is varying from 1.12 to 1.08 in case of 3-level inverter and in case of 2-level inverter it is varying from 1.13 to 1.05 . From this it is concluded that flux ripple is decreased considerably for 3level inverter compared to 2-level inverter.

In fig 9 FFT analysis of stator current for 3- level, 2-level fed induction motor are shown. The comparison is carried for an identical machine at identical conditions. From fig. 9 THD for 2-level inverter is $7.86 \%$ and it is 3.76 for 3 -level inverter. From this it is concluded that stator current distortions are decreased considerably for 3-level inverter compared to 2-level inverter.

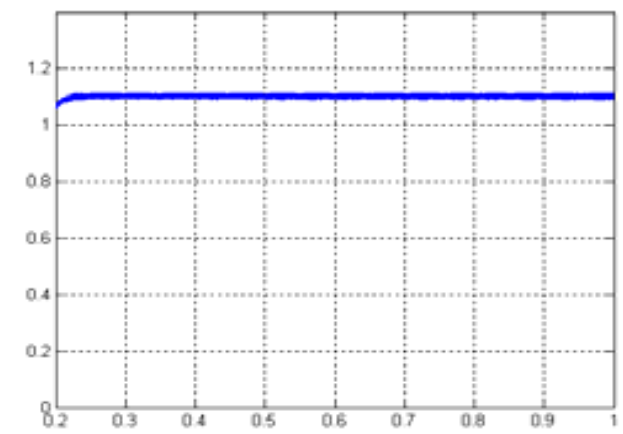

(a) DTC-SVM (Two-level Inverter)

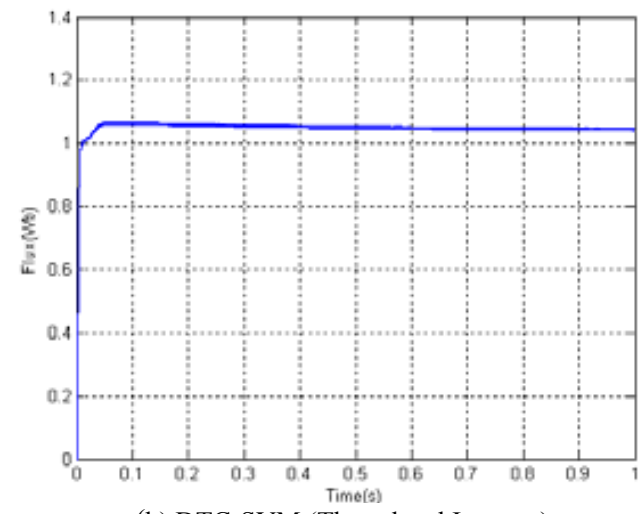

(b) DTC-SVM (Three-level Inverter)

Fig. 8. Stator Flux responses

From fig.10 Simulation results for stator flux trajectory for 3-level, 2-level inverter fed induction motor are shown. The comparison is carried for a given machine at similar conditions and it is observed that the stator flux trajectory in the three-level scheme has been reduced significantly .

Comparison of DTC for 2 level inverter fed induction motor drive and 3 level inverter fed IM drive is shown in table 2.From the table it is concluded that that employment 3 level inverter instead of 2 level one gives performance of the drive with far lower torque ripple and flux ripple and a lower harmonic content in stator currents and stator voltages.

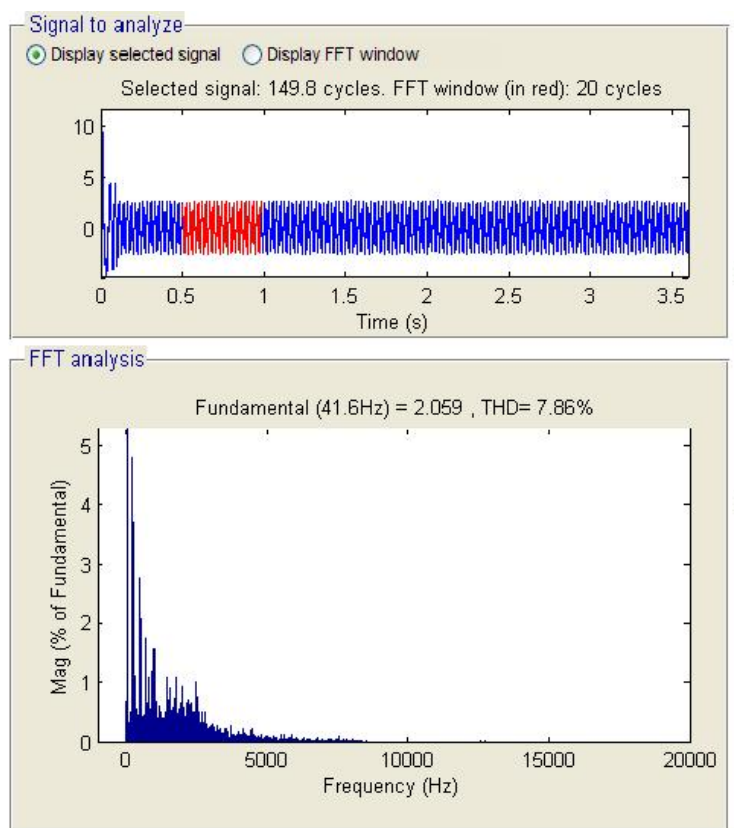

(a) DTC-SVM (Two-level Inverter) 


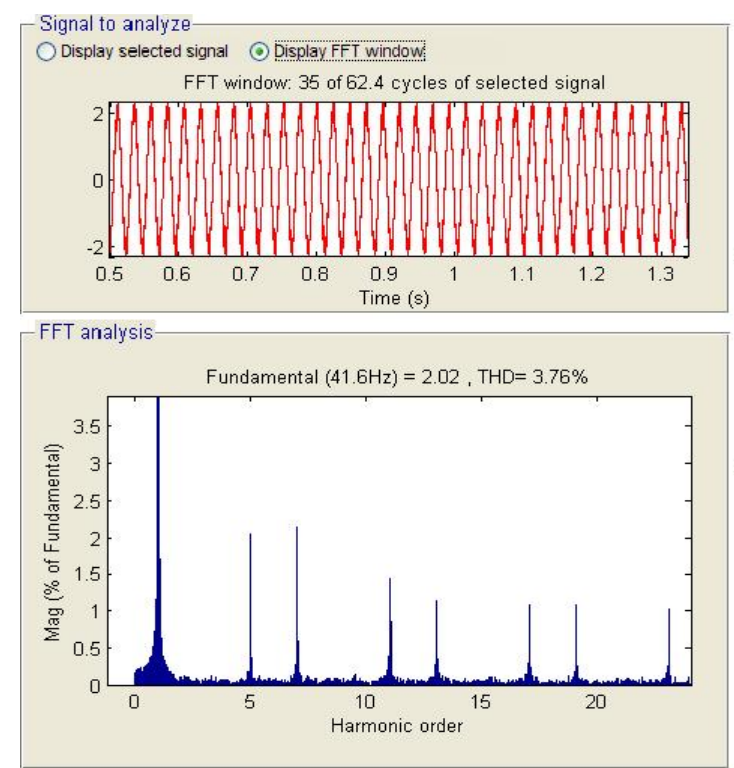

(b) DTC-SVM (Three-level Inverter) Fig. 9. Line current and Harmonic spectrum

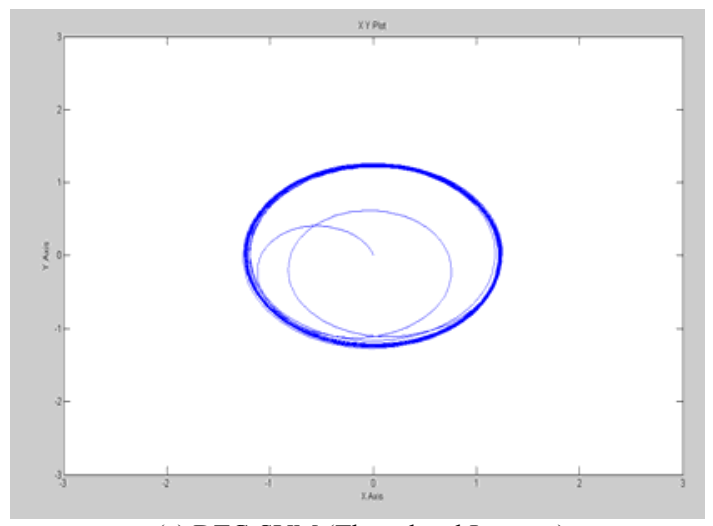

(a) DTC-SVM (Three-level Inverter)

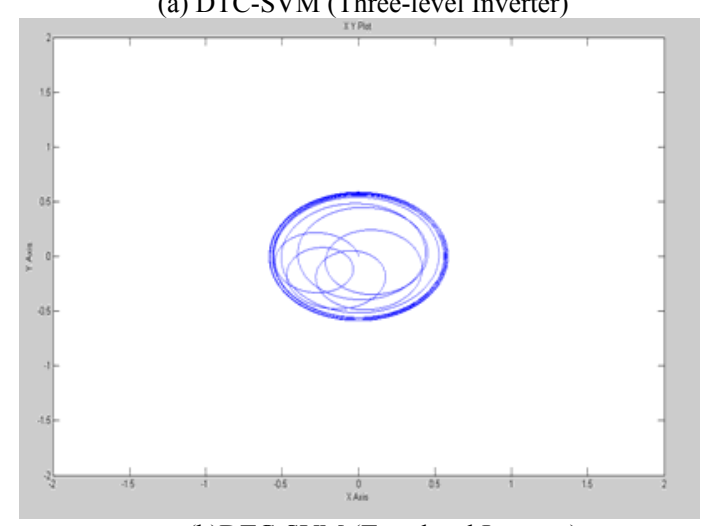

(b)DTC-SVM (Two-level Inverter)

Fig. 10. Simulation results for stator flux trajectory

Table II: Comparison of results between 2-level and 3-level inverter fed Induction Motor Drive

\begin{tabular}{|c|c|c|}
\hline Parameter & $\begin{array}{c}\text { DTC for 2-level } \\
\text { inverterfed IM Drive }\end{array}$ & $\begin{array}{c}\text { DTC for 3-level } \\
\text { inverterfed IM Drive }\end{array}$ \\
\hline Torque Ripple(N-m) & 7.5 & 3.3 \\
\hline Flux Ripple(web) & 1.13 to 1.05 & $1.12-1.08$ \\
\hline $\begin{array}{c}\text { Stator Current Distortion } \\
\text { (T.H.D) }\end{array}$ & $7.86 \%$ & $3.76 \%$ \\
\hline
\end{tabular}

\section{CONCLUSION}

In this paper the DTC principle is presented and it is shown that with a simple SVPWM algorithm for a threelevel inverter based on a standard two-level inverter we can implement this method easily. The simulation results obtained for the DTC-SVM with three level inverter illustrate a considerable reduction in torque ripple and flux ripple compared to the existing DTC-SVM utilizing two level inverter. The proposed algorithm is a natural extension of the classical DTC with a 2-level inverter and does not require any predictive algorithms. The results of the simulation show that employment 3-level inverter instead of 2-level one with such control algorithm permits to obtain the same dynamical performance of the drive with far lower torque ripple and flux ripple and a lower harmonic content both in the stator voltages and currents. These advantages counter balance the increased complexity of the circuitry 3level converter. On the other hand the reduction of harmonic content permits corresponding cut back of the expenses on the filtering devices. Control algorithms computational burden is practically same as the one of the classical DTC without need of powerful processors when implemented in hardware.

\section{APPENDIX}

Motor parameter used in the simulation:

Induction Motor Detail

400V, 10HP (7.5KW), 4 Poles, $1440 \mathrm{rpm}$

Stator resistance

$0.7384 \mathrm{ohm}$

Stator inductance

$3.045 \mathrm{mH}$

Moment of inertia

0.0343 kg.m2

Friction coefficient

0.000503 N.m.s $/ \mathrm{rad}$

\section{ACKNOWLEDGMENT}

The authors would like to thank the Management and the Principal of Vignan's Lara Institute of Technology \& Science for their Constant support and valuable guidance throughout our study.

\section{REFERENCES}

[1] Y.P. Obulesu, M.V.Kumar, "Design and simulation of direct torque control of Induction Motor drive using Matlab/Simulink," International Journal of Power and Energy Systems, Vol. 27, No.2, 2007.

[2] G. Buja, M. P. Kazmierkowski, "Direct torque control of PWM inverter fed AC motors - A Survey," IEEE Transaction on Industrial Electronics, Vol. 51, no. 4, pp. 744-757, August 2004.

[3] T. G. Habetler, F. Profumo, M.Pastorelli, L. Tolbert "Direct torque control of induction machines using space vector modulation,"IEEE Transaction on Industry Applications, Vol. 28, no. 5, pp. 1045-1053, septembre/October 1992.

[4] J. L. Romeral, A. Arias, E. Aldabas, M. G.Jayne "Novel direct torque control (DTC) scheme with fuzzy adaptive torque ripple reduction,'IEEE Transaction on Industrial Electronics, Vol. 50, no. 3, pp. 487-492, June 2003.

[5] I. G. Bird, H. Zelaya "Fuzzy logic torque ripple reduction for DTC based AC dives,'IEE Electronics Letter, Vol. 33, no. 17, August 1997.

[6] J. Kang, S. Sul"New direct torque control of induction motor for minimum torque ripple and constant switching frequency,"IEEE Transaction on Industry Applications, Vol. 35, no. 5, pp. 1076-1082, septembre/October 1999.

[7] A. Gupta, A. M. Khambadkone"A space vector pwm scheme for multilevel inverters based on two-level space vector pwm,'IEEE Transaction on Industrial Electronics, Vol. 53, October 2006.

[8] Xavier Del Toro Garcia, Antoni Arias, Marcel G. Jayne, Phil A Witting, Vicenc M. Sala, Jose Luis Romeral "New DTC Control Scheme for Induction Motors fed with a Three Level Inverter" AUTOMATIKA 46(2005) 1-2, 73-81, ISSN 0005-1144.

[9] A. Iqbal, A. Lamine, I. Ashraf, Mohibullah Matlab/Simulink model of space vector pwm for three-phase voltage source inverter'IEEE Tran. 
[10] Takahashi, T. Noguchi, "A new quick response and high-efficiency control strategy of induction motor", IEEE Trans. On IA, Vol.22, $\mathrm{N}^{\circ} .5$, Sept/Oct 1986, PP.820-827.

[11] M. Depenbrock, "Direct self - control (DSC) of inverter - fed induction machine", IEEE Trans. Power Electronics, Vol.3, N $\mathrm{N}^{\circ} .4$, Oct 1988, PP.420-829.

[12] D. Casadei, F. Profumo, G.Serra and A.Tani, "FOC and DTC: Tox Viable Schemes for induction Motors TorqueControl", IEEE Trans. Power Electronics. On PE, Vol.17, No.5, Sept2002,

[13] D. Casadei and G.Serra, "Implementation of direct Torque control Algorithme for Induction Motors Based On Discrete SpaceVector Modulation", IEEE Trans. PowerElectronics. Vol.15, $\mathrm{N}^{\circ} .4$, JULY2002,

[14] A.A.Pujol, Improuvent in direct torque control of induction Motors", Thèse de doctorat de L'UPC, ovembre2000

[15] R.Toufouti ,H.Benalla, and S.Meziane "Three-Level Inverter With Direct Torque Control For Induction Motor", World Conference on Energy for Sustainable Development: Technology Advances and Environmental Issues, Pyramisa Hotel Cairo - Egypt, 6 - 9 December 2004.

[16] JIA-QIANG YANG, JIN HUANG " A New Full-Speed Range Direct Torque Control Strategy for Induction Machine", Proceedings of the Third International Conference on Machine Learning and Cybernetics, Guang.

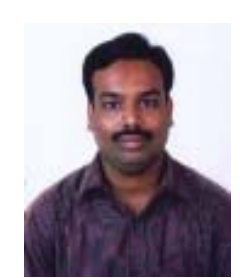

O.Chandra Sekhar received his B.Tech degree in Electrical \& Electronics Engineering from Narayana Engineering College, Nellore,India in 2005 and M.Tech with power Electronics and Electrical Drives from Vignan's Engineering College, Vadlamudi, India in 2008.He has been with Vignan's Lara Institute of Technology and Science, Vadlamudi as Associative Professor. Presently he is a part-time research student at J.N.T.U College of Engineering, Hyderabad- 500072, India, working towards his doctoral degree.

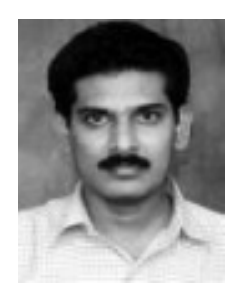

K.Chandra Sekhar received his B.Tech degree in Electrical \& Electronics Engineering from V.R.Siddartha Engineering College, Vijayawada, India in 1991 and M.Tech with Electrical Machines \& Industrial Drives from Regional Engineering College, Warangal, India in 1994. From 1994 to 1995, he was the Design \& Testing Engineer in Maitreya Electricals (P) Ltd. Vijayawada. From 1995 to 2000, he worked with Koneru Lakshmaiah College of Engineering as a Lecturer, since 2000, he has been with R.V.R \& J.C.College of engineering as Professor.. He Received the $\mathrm{PhD}$, degree from the J.N.T.U College of Engineering, Hyderabad- 500072, India, in 2007. His Research interests are Power Electronics, Industrial Drives \& FACTS Devices. 